geies vom 27. 9pril 1894 Cinflus gewonnen, 3. B. burd bie

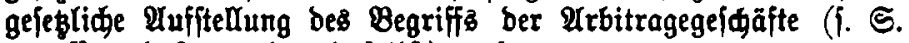
485 ff. und Formulare bafelbit) u. \{. w.

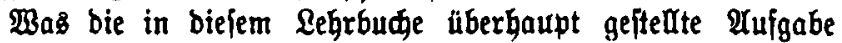
unb bie $\mathfrak{A r t}$ unb $\mathfrak{B e i f e}$ bes $\mathfrak{B e r}\{u$ has, bieje zu erfüllen, an. langt, namentfia bas fiđ hieraus crgebende Berbältnis bee: felben zur weiten jurijtijøen Spezialliteratur unb zu ber fort-

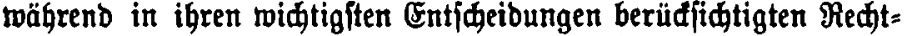

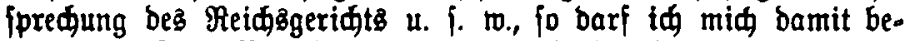
gnügen, auf bie Borreben ber vorausgehenben $\mathfrak{A}$ uflagen, namentlid ber vierten zu verweijen.

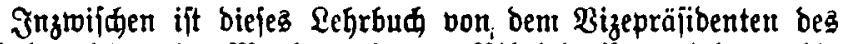

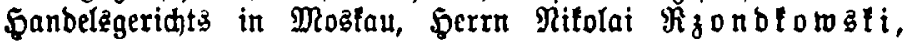
unter Mitrirfung meines Serrn Follegen an ber Univerfität

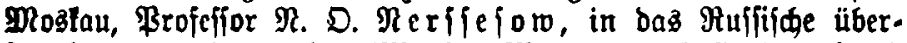
fefgt beraużgegeben worben (MRoşłau, Mamontow \& (Eie.), wägreno bas VI. Rapitel, baz Єeereht, bon bem Florentiner $\mathscr{A}$ bootaten Đerrn Torquato Bi $i$ nnini in bas Stalienifde überiegt wurbe

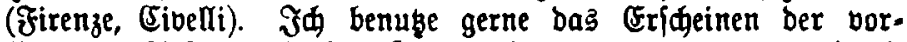

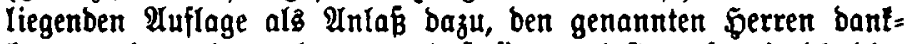
bar anerfennenb gu bezeugen, baß fie, menigftens poweit ic bies

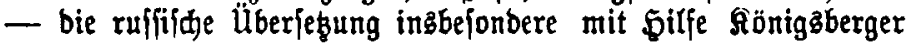
\{pradtunbiger Rollegen - zu beurteilen vermag, mit flarem Berjtänoniz treu und fađjgemäß überięt haben.

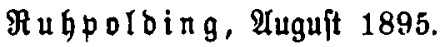

\title{
Gaxt gaxeis.
}

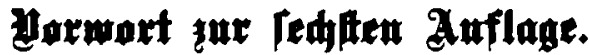

Mas innerbalb ber brei Sahre, welde jeit bem Erjakeinen ber vorigen 2 uflage biejes \&egrbuds verflofien find, von ber Deutiden Bejesgebung geidaffen wurbe, ift fo bebeutend, baj eine böllige Umarbeitung bes eriten Teilez biejes $\mathfrak{B} u(h \bar{b}$, bez

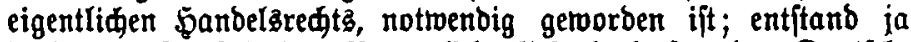

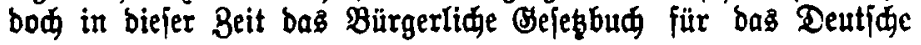




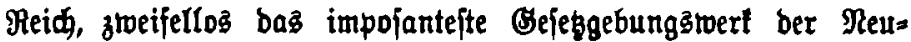
zeit, unb im Ânidluffe baran eine Umgeftaltung bes Sanbels=

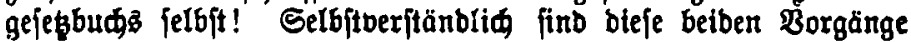

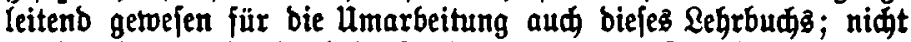
minber jelbftberftänbliđ barf i bas \$̧anbeläredt berührenben Neuerungen unjerer Bejeggebung,

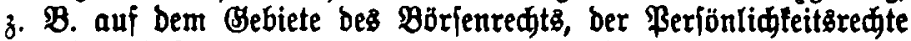

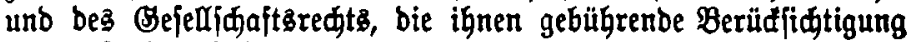
hier gefunden haben.

In Bejug auf bie Methobe ber Darjtellung, inşbejonbere bie Seranziehung und Erwähnung ber Riteratur unb ber Rectfpredung, unterideibet fid bie vorliegende âdugabe nidt von ben vorhergehenben, auf beren Bortworte id mir aud im übrigen zu verweifen geftatte.

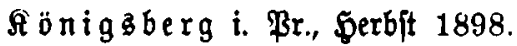

Gart Gareis.

\section{Dlaxwout ģur fiethenten Muflage.}

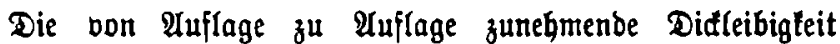

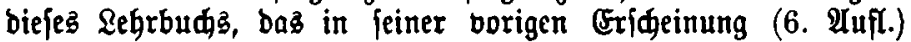
bereits an 1000 Seiten umfaßste, ift, wie ntebrfach gcäunert sourbe, unangenehm empjunden worben; auf

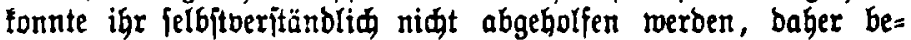

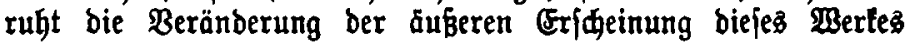
in ber vorliegenden fiebenten $\mathfrak{A} u$ jlage nur zum geringiten Teile

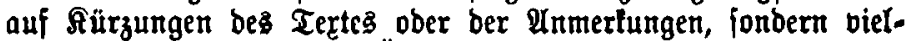

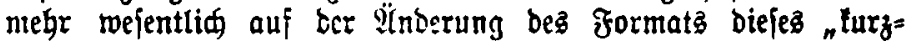
gefaßsten Rehrbuめs". Bmed uno Methobe ber Daritellung

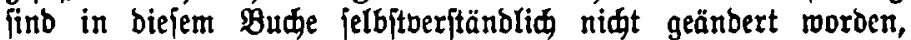
fo jei benn hinfidtlid biejer auf bie Borreben ber vorigen ITujlagen berviejen. Qiteratur, neue Bejeggebung und neue Ređtjprectung find wie feither berüuffidtigt und nadgetragen; tiefgebende भ̈nderung hat zuforge gefeglider Reugeftaltung bas 